\title{
Capital social e os desafios do Corredor Bioceânico
}

\author{
Capital and the challenges of Bioceanic Highroad Crossing \\ Capital social y los desafíos de la Ruta Bioceanica
}

\author{
Maria Geralda Miranda ${ }^{1}$ \\ Reis Friede ${ }^{1}$ \\ Katia Avelar ${ }^{1}$
}

Recebido em 28/02/2019; revisado e aprovado em 28/04/2019; aceito em 19/06/2019 DOI: http://dx.doi.org/10.20435/inter.v20iespecial.2538

\begin{abstract}
Resumo: O Corredor Bioceânico, que ligará o Centro-Oeste brasileiro ao Oceano Pacífico, proporcionará a implementação de intercâmbios econômicos, sociais, turísticos e culturais, conforme declarações de autoridades governamentais, empresários, jornalistas e outros. O presente estudo visa verificar a tônica dos discursos oficiais a respeito de tal Corredor, no que tange, principalmente, ao desenvolvimento sustentável e à formação de capital social, considerados fundamentais para a sustentabilidade de empreendimentos como este. Para embasar o estudo, além das discussões acerca do capital social, a partir de Putnam, considerou-se relevante pontuar questões presentes na Agenda 2030 da Organização das Nações Unidas para o Desenvolvimento Sustentável, ONU, principalmente ao que se refere ao objetivo número 8, que traz orientações em relação ao crescimento econômico sustentado, inclusivo e sustentável.
\end{abstract}

Palavras-chave: Agenda 2030 da ONU; desenvolvimento sustentável; comunidade cívica.

Abstract: The Bioceanic Highroad Crossing, which will connect the Brazilian Midwest to the Pacific Ocean, will provide for the implementation of economic, social, tourism and cultural exchanges, according to statements by government officials, businessmen, journalists and others. The present study aims to verify the tone of the official discourses regarding such Hignroad Crossing, in what concerns, mainly, the sustainable development and the formation of social capital, considered fundamental for the sustainability of ventures like this one. In order to base the study, in addition to the discussions on social capital, from Putnam, it was considered relevant to point out issues present in the Agenda 2030 of the United Nations Organization for Sustainable Development, UN, especially with regard to objective number 8, which provides guidelines for sustained, inclusive and sustainable economic growth.

Keywords: UN Agenda 2030; Sustainable development; civic community.

Resumen: La Ruta Bioceánica, que conectará el Centro-Oeste brasileño al Océano Pacífico, proporcionará la implementación de intercambios económicos, sociales, turísticos y culturales, según declaraciones de autoridades gubernamentales, empresarios, periodistas y otros. El presente estudio busca verificar la tónica de los discursos oficiales acerca de tal Ruta, en lo que se refiere principalmente al desarrollo sostenible ya la formación de capital social, considerados fundamentales para la sostenibilidad de emprendimientos como éste. Para basar el estudio, además de las discusiones sobre el capital social, a partir de Putnam, se consideró relevante puntuar cuestiones presentes en la Agenda 2030 de la Organización de las Naciones Unidas para el Desarrollo Sostenible, ONU, principalmente al que se refiere al objetivo número 8, que trae orientaciones en relación al crecimiento económico sostenido, inclusivo y sostenible

Palabras clave: Agenda 2030 de la ONU; desenvolvimiento sustentable; comunidad cívica.

\section{INTRODUÇÃO}

Entre os objetivos do Corredor Bioceânico estão a conexão, por meio de corredor rodoviário, dos territórios de quatro países (Brasil, Paraguai, Argentina e Chile), a redução do tempo de deslocamento de carga, a melhoria logística de transporte, a elevação da competitividade das exportações para a Ásia dos quatro países, bem como o fomento ao turismo e o estímulo à criação de novos fluxos de comércio regional e, ainda, a integração entre estes países.

\footnotetext{
${ }^{1}$ Centro Universitário Augusto Motta (UNISUAM), Rio de Janeiro, Rio de Janeiro, Brasil.
} 
A Agenda $2030^{2}$, em seu Objetivo número 8, traz direcionamentos aos Estados em relação ao crescimento econômico sustentado, inclusivo e sustentável. Tal objetivo traz vários itens, entre eles, vale destacar o 8.1 que prevê crescimento econômico per capita, de acordo com as circunstâncias nacionais e, em particular, um crescimento anual de pelo menos $7 \%$ do Produto Interno Bruto (PIB), nos países menos desenvolvidos".

O 8.2, por sua vez, prevê políticas orientadas para o desenvolvimento de atividades produtivas, geração de emprego decente, empreendedorismo, criatividade e inovação, e incentivo à formalização e ao crescimento de micro, pequenas e médias empresas, inclusive por meio do acesso a serviços financeiros. Já o 8.7 orienta os governos a tomar medidas imediatas e eficazes para erradicar o trabalho forçado, acabar com a escravidão moderna e o tráfico de pessoas, e assegurar a proibição e eliminação das piores formas de trabalho infantil, incluindo recrutamento e utilização de crianças-soldado, e até 2025 acabar com o trabalho infantil em todas as suas formas.

O 8.8 prevê a proteção dos direitos trabalhistas e a promoção de ambientes de trabalho seguros e protegidos para todos os trabalhadores, incluindo os trabalhadores migrantes, em particular as mulheres migrantes, e pessoas em empregos precários.

Por seu turno, o 8.9 orienta acerca da implementação de políticas para promover o turismo sustentável, que gera empregos e promove a cultura e os produtos locais. E o 8 . 10 direciona para o fortalecimento da capacidade das instituições financeiras nacionais para incentivar a expansão do acesso aos serviços bancários, de seguros e financeiros para todos.

Como se vê nos itens selecionados do Objetivo no 8 da Agenda 2030 da ONU, o Corredor Bioceânico configura-se como um empreendimento cingido às necessidades de desenvolvimento dos países parceiros, Brasil, Paraguai, Argentina e Chile. Daí a importância de discutir o assunto em todos os seus aspectos, gargalos e implicações, uma vez que o desenvolvimento econômico precisa estar associado ao Índice de Desenvolvimento Humano (IDH) ${ }^{3}$.

Este estudo pretende, por meio de reflexões acerca dos discursos públicos, divulgados em jornais e sites oficiais, contribuir com os estudos sobre os impactos sociais e ambientais provocados nos territórios a partir da efetivação do Corredor Bioceânico.

\footnotetext{
${ }^{2}$ Os 17 Objetivos de Desenvolvimento Sustentável e 169 metas que estamos anunciando hoje estimularão a ação para os próximos 15 anos em áreas de importância crucial para a humanidade e para o Planeta, como assegurar que todos os seres humanos possam desfrutar de uma vida próspera e de plena realização pessoal, e que o progresso econômico, social e tecnológico ocorra em harmonia com a natureza. [...] buscam concretizar os direitos humanos de todos e alcançar a igualdade de gênero e o empoderamento das mulheres e meninas. Eles são integrados e indivisíveis, e equilibram as três dimensões do desenvolvimento sustentável: a econômica, a social e a ambiental. ORGANIZAÇÃO DAS NAÇÕES UNIDAS, ONU, Disponível em https://nacoesunidas.org/pos2015/agenda2030/.n. Acesso em: 24 abr. 2019.

3 IDH: Índice de Desenvolvimento Humano. Trata-se de um indicador de desenvolvimento humano, da Organização das Nações Unidas, utilizado para avaliar a qualidade de vida e o desenvolvimento de um município ou região. Anualmente é elaborado o Relatório de Desenvolvimento Humano (RDH) pelo Programa das Nações Unidas para o Desenvolvimento (PNUD) com base em três critérios (Saúde, Educação e Renda) Saúde, baseado na expectativa de vida; Educação: média de anos de estudo (adultos) e anos esperados de escolaridade (crianças). Renda, medido pela Renda Nacional Bruta (RNB) com base na Paridade de Poder de Compra (PPC) por habitante. O IDH varia entre 0 (nenhum desenvolvimento humano) e 1 (desenvolvimento humano total), revelando que quanto maior a proximidade de 1 , mais desenvolvido é o país (DAWALIBI AT AL, 2014).
} 


\section{O CORREDOR RODOVIÁRIO BIOCEÂNICO NOS DISCURSOS OFICIAIS}

Na página da Transparência Pública do Governo de Mato Grosso do Sul se lê a chamada para o Primeiro Seminário do Corredor Rodoviário Bioceânico, ocorrido em 2016. No link, denominado Antecedentes, informa-se que em 21 de dezembro de 2015, os presidentes do Brasil, Argentina, Chile e Paraguai aprovaram a Declaração de Assunção, por meio da qual foi criado Grupo de Trabalho para realizar estudos técnicos e empreender ações que viabilizassem o Corredor Rodoviário Bioceânico Porto Murtinho-Portos do Norte do Chile (GOVERNO DO ESTADO MATO GROSSO DO SUL, 2016).

Ainda no site, no link denominado Foco de cada região descreve-se de maneira resumida aquilo que seria o objetivo imediato dos participantes. O governo do Estado de Mato Grosso do Sul vislumbra "fornecer ao agronegócio uma saída para o Pacífico, permitindo tanto o escoamento da produção quanto a importação direta de insumos a preços mais competitivos". Já o objetivo do governo do Chile, conforme descrição no site, é "incrementar o comércio com os países da região, consolidando-se como importante plataforma logística".

O governo da Argentina, por sua vez, tem como objetivo "fortalecer a implementação do Plano Belgrano ${ }^{4}$, que prevê integrar o Norte do país, por meio da ligação das províncias de Salta e Jujuy", e o governo do Paraguai ambiciona que o Corredor Rodoviário permita a melhoria da infraestrutura e integre a região do Chaco ao resto do país (GOVERNO DO ESTADO MATO GROSSO DO SUL, 2016).

Obviamente que as ideias dos gestores públicos acerca dos objetivos e possibilidades da Rota foram ampliando, num amadurecimento profícuo, na medida em que as etapas foram se concretizando, mas percebe-se pelos objetivos inscritos no banner do seminário, divulgado no site da Transparência, que o governo de Mato Grosso concentrou-se em um "objetivo macroeconômico", vinculado às demandas do agronegócio (exportação de grãos), sem mencionar outros alcances, naquele momento, que tal empreendimento poderia oferecer ao Estado. O Seminário foi realizado no final de 2016, mas somente em 2018, aprovou-se, no Senado, a proposta de construção da ponte entre o Brasil e o Paraguai.

Na página do Senado em 17 de abril de 2018 se lê que "o Senado aprovou nesta terça-feira (17) proposta que permite a construção de uma ponte rodoviária entre Brasil e Paraguai (PDS 17/2018). A ponte faz parte do chamado Corredor Bioceânico, e ligará as cidades de Porto Murtinho, em Mato Grosso do Sul, e Carmelo Peralta, no Paraguai. A obra deverá ser custeada em partes iguais pelos governos das duas nações. O ato internacional foi firmado em Brasília,

\footnotetext{
${ }^{4}$ O Plano Belgrano de desenvolvimento de infraestrutura viária, ferroviária, etc visa integrar o Norte argentino e prevê um investimento de US\$ 16 bilhões em dez anos e a constituição de um Fundo de Reparação Histórica de 50 bilhões de pesos. Seu eixo é um gasto de US\$ 10 bilhões destinado a transformar a Ruta 9, que liga as províncias de Córdoba e Salta, a Ruta 34 (Rosario-La Banda-Salta-Orán) e a Ruta 14 (Paso de los Libres-Posadas) em rodovias, além de uma nova ponte Resistência-Corrientes. Devem ser acrescentados US\$ 4 bilhões para a restauração do ramal principal da Ferrovia Mitre (Tucumán-Rosario-Buenos Aires-La Plata) que se soma ao programa de modernização em andamento do ramal Belgrano Cargas, que atravessa 17 províncias. O aspecto produtivo do Plano Belgrano começa com uma elevação do corte dos biocombustíveis nas motonaftas (de 10\% para 15\%) e pressupõe a eliminação dos impostos à exportação de trigo e milho e de todas as economias regionais, e uma diminuição de 5\% para a soja. O protagonista do Plano Belgrano é necessariamente a produção agroalimentar que, a partir do salto tecnológico ocorrido nos últimos 20 anos, transformou-se principalmente em um processo de desenvolvimento urbano integrado à indústria e aos serviços. CASTRO, José. O Plano Belgrano, chave para o agronegócio no Norte da Argentina. Disponível em: https://www.clarin.com/clarin-em-portugues/plano-belgrano-agronegocios-norteargentina_0_HkeceaOwXx.html. Acesso em: 24 abr. 2019.
} 
em 8 de junho de 2016.

Também o Campo Grande News, em 27 de dezembro de 2018, publica matéria, com destaque para dados estatísticos elaborados pelo Sindicato das Empresas de Transporte de Cargas e Logística (Setlog/MS), que mostram as vantagens econômicas para o Estado: "a construção da ponte de concreto sobre o Rio Paraguai, em Porto Murtinho, prevista para conclusão em 2021 [...] representará um incremento no primeiro ano de U\$ 50 milhões de dólares (cerca de $\mathrm{R} \$ 200$ milhões) na economia no Estado" (CAMPO GRANDE NEWS, 2018) ${ }^{5}$.

O dado estatístico que demonstra a importância do corredor transfronteiriço para o Estado e para o país é uma das conclusões do estudo de viabilidade econômica da Rota, elaborado pelo Sindicato das Empresas de Transporte de Cargas e Logística (Setlog/MS). O presidente da entidade, Cláudio Cavol, estima que, antes mesmo da finalização do asfalto no trecho paraguaio, que atravessa o Chaco, o volume de cargas será intensificado com a ligação fluvial. (CAMPO GRANDE NEWS, 2018).

Já o jornal Correio do Estado ${ }^{6}$, em 13 de dezembro de 2018, informa que Fernando Schmidt, embaixador do Chile no Brasil, em visita a Campo Grande, fez palestra na Universidade Federal do Estado e reuniu-se com o governador do Estado e com o prefeito da cidade de Campo Grande. Segue afirmando que diferente dos encontros anteriores com autoridades e empresários brasileiros, desta vez "o representante do governo chileno exaltou a possibilidade de ganhos não somente no comércio e escoamento de produções, mas no intercâmbio de turistas de todos os países envolvidos na Rota". Nas palavras do embaixador: "há inúmeras atrações que podem receber muito mais visitantes no caminho entre Mato Grosso do Sul e as cidades portuárias de Iquique e Antofagasta, no Oceano Pacífico". Ainda citando o embaixador chileno, o jornal Correio do Estado afirma que

Além de Bonito e do Pantanal Sul-Mato-Grossense, Schmidt lembra que o Chaco Paraguaio, por onde a rodovia passará, também é um local belo e inexplorado. Também cita importantes cidades do norte argentino, dotadas de vasta riqueza gastronômica e cultural, com belas catedrais, caso de Salta e San Salvador de Jujuy. [...] Entre as duas províncias argentinas e as cidades litorâneas chilenas, ainda existem muitas outras atrações, como por exemplo, salares, a imponente Cordilheira dos Andes, o deserto do Atacama, além de inúmeros observatórios astronômicos. (CORREIO DO ESTADO, 2018).

O Jornal TopMidia News também publicou matéria com a manchete "Rota Bioceânica injetará R\$ 200 milhões na economia de Mato Grosso do Sul: Em três anos o Estado se tornará um polo concentrador do comércio latino-americano". O jornal também replica ou reverbera o discurso oficial:

Para o governo de Mato Grosso do Sul [...], o novo cenário que se desenha com a efetivação da Rota Bioceânica [...] transformará a economia regional, beneficiando não apenas o agronegócio e a produção industrial, mas a cadeia que envolve o turismo e também o

\footnotetext{
${ }^{5}$ Manchete: Bioceânica injetará R\$ 200 milhões na economia de MS no primeiro ano. Disponível em: https://www. campograndenews.com.br/cidades/interior/bioceanica-injetara-rs-200-milhoes-na-economia-de-ms-no-primeiroano. Acesso em: 24 abr. 2019.

${ }^{6}$ Manchete da matéria: Rota Bioceâncica será nova fronteira do turismo em quatro países, diz embaixador Fernando Schmidt, embaixador do Chile no Brasil. Disponível em: https://www.correiodoestado.com.br/cidades/rotabioceanica-sera-uma-fronteira-do-turismo-em-quatro-paises-diz/343038/. Acesso em: 24 abr. 2019.

${ }^{7}$ Disponível em https://www.topmidianews.com.br/economia/rota-bioceanica-injetara-r-200-milhoes-na-economiade-ms/103315/. Acesso em: 26 abr. 2019.
} 
intercâmbio cultural e tecnológico. As projeções do Governo do Estado e do setor privado são otimistas ao apontarem um novo ciclo de forte crescimento de Mato Grosso do Sul (TOPMIDIA NEWS, 2019).

Para Jaime Verruck, secretário de Estado de Meio Ambiente, Desenvolvimento Econômico, Produção e Agricultura Familiar (Semagro), Porto Murtinho deixou de ser uma região isolada para se tornar estratégica. "Murtinho vem se consolidando como um 'hub' logístico dentro da América do Sul", afirma, citando os investimentos do Estado na reativação do transporte fluvial, pelo rio Paraguai, e a ponte internacional, vital para viabilizar a Rota Bioceânica. (TOPMIDIA NEWS, 2019).

Também Viegas (2018) transcreve na página do $\mathrm{G}^{8}$ as palavras de Jaime Verruck secretário de Meio Ambiente, Desenvolvimento Econômico, Produção e Agricultura Familiar de Mato Grosso do Sul (Semagro):

O estado vai se tornar um grande hub para as exportações que vão seguir pelos portos chilenos. Esse é o primeiro ponto. Muita carga vai centralizar aqui. A importação também. Existe uma grande possibilidade de Mato Grosso do Sul também ser um hub de distribuição de produtos importados para todo o país. De produtos que são oriundos da China hoje e que vão vir pela Rota, chegando a Campo Grande e daqui sendo distribuídos para o Brasil.

Novamente, o Jornal Correio Brasiliense, ${ }^{9}$ em 24 de janeiro de 2019, publica matéria, assinada por Silvio Andrade, desta vez, com destaque para a localidade Porto Murtinho: "Um dos últimos municípios do Estado a ter o acesso pavimentado - em 2003 foi inaugurado o trecho final de asfalto da BR-267, de $213 \mathrm{~km}$-, Porto Murtinho rompe o isolamento histórico para se tornar um dos principais entrepostos comerciais de Mato Grosso do Sul”. E segue:

O extremo sudoeste, na fronteira com o Paraguai, saiu da condição de fim de linha para centro de uma Rota rodo-fluvial que barateia os custos e potencializa a produção primária de Mato Grosso do Sul no competitivo centro consumidor da Europa e Ásia. Porto Murtinho terá, em breve, quatro portos operando na Hidrovia do Paraguai e, em 2023, será o eixo do corredor bioceânico (Atlântico-Pacífico) por rodovia, com a construção da ponte sobre o Rio Paraguai. (ANDRADE, 2019, grifo nosso)

As palavras do Prefeito de Porto Murtinho, citadas pelo jornal, reafirmam a importância do Corredor Bioceânico para a cidade. Ele acredita em uma transformação sem precedentes em sua região, em médio prazo, que beneficiará “a população com a geração de empregos - o fechamento do frigorífico local desempregou centenas de trabalhadores. 'O complexo portuário será a nossa redenção'. Delevatti pretende reduzir o ISS (Imposto Sobre Serviços) de 5\% para 2\% para atrair novos investidores" (ANDRADE, 2019) .

\footnotetext{
${ }^{8}$ VIEGAS, Andersom. Viabilização da rota bioceânica deve transformar MS em 'hub' de exportação e importação, prevê secretário. Disponível em: https://g1.globo.com/ms/mato-grosso-do-sul/noticia/2018/12/24/viabilizacaoda-rota-bioceanica-deve-transformar-ms-em-hub-de-exportacao-e-importacao-preve-secretario.ghtml. Acesso em: 24 abr. 2019.

${ }^{9}$ ANDRADE, Silvio. Porto Murtinho sai do isolamento e vira polo de exportação. Disponível em: https://www. correiodoestado.com.br/economia/porto-murtinho-sai-do-isolamento-e-vira-polo-de-exportacao/349721/. Acesso em: 26 abr. 2019.
} 


\section{CAPITAL SOCIAL, DESENVOLVIMENTO ECONÔMICO E HUMANO}

Como observa Duque (2014, p. 1), são diversos os autores que tratam o capital social como um recurso necessário e imprescindível para a configuração de um desenvolvimento sustentável. O principal argumento é de que ele é capaz "de promover a interação entre pessoas, estruturas e instituições, sustentadas pela confiança mútua, cooperação, civismo e participação". Diz também o autor que a ideia que subjaz a este princípio é a de rede social, que estimulada pela confiança e cooperação, acaba produzindo uma melhoria do social.

Duque (2014) dialogando com Coleman (1990, p. 300) argumenta que a noção de capital social surge como uma resposta a um dos mais decisivos mitos fundadores da civilização moderna: o de que a sociedade é um "conjunto de indivíduos independentes, cada um agindo para alcançar objetivos a que chegam independentemente uns dos outros". Os diferentes relatórios de agências internacionais que trabalham temas ligados ao capital social "partem, de forma geral, da constatação de que os atores econômicos não são por si só suficientes para gerar crescimento socialmente justo e ambientalmente sustentável" (DUQUE, 2014, p. 2).

Putnam (2006) conceitua capital social como sendo as práticas sociais, normas e relações de confiança presentes entre cidadãos de uma determinada sociedade. O elemento basilar e primordial para o autor é a confiança, exatamente porque é capaz de promover a cooperação. "Quanto mais elevado o nível de confiança numa comunidade, maior a probabilidade de haver cooperação. E a própria cooperação gera confiança” (PUTNAM, 2006, p. 180).

Taveira (2016, p. 14) afirma que no pensamento de Putnam sobre o capital social, a confiança implica uma previsão de comportamento dos atores, de forma independente. "A relação somente é estabelecida no que se confia (pessoas, entidades, organizações, projetos, ideias)". A capacidade, a disposição, as alternativas e as consequências desses atores podem passar ou não confiança, sendo resultado de um convívio direto.

O estudo de Putnam sobre o capital social nasceu de uma preocupação em relacionar a teoria e a prática na democracia. A sua inquietação apontava para a seguinte questão: a reforma política e o progresso material são suficientes para assegurar a saúde das democracias nas dimensões política, social e econômica (BAIARDI, 1997).

As pesquisas empíricas de Putnam e de seus colaboradores foram realizadas na Itália, mas contribuem de maneira significativa para a compreender o funcionamento das instituições e os laços fundamentais para criação e manutenção de redes e, portanto, de desenvolvimento, em qualquer parte. Para entender os resultados obtidos pelo pesquisador e sua equipe, vale mencionar que na década de 1970, na Itália, por meio de reforma administrativa, criaram-se 20 regiões administrativas, que implicaram no nascimento de novos governos regionais.

Para a sua pesquisa, Putnam criou alguns indicadores ${ }^{10}$ para avaliar o desempenho institucional dos novos governos e entender o processo de adaptação das novas regiões e seus desempenhos a partir dos governos autônomos. A avaliação das regiões a partir dos indicadores mostrou resultados diversos. Os que tiveram melhor desempenho institucional foram os da Itália Setentrional, ao passo que os que tiveram pior desempenho foram os da Itália Meridional. A

\footnotetext{
${ }^{10}$ Os índices avaliados foram: legislação reformadora, creches, habitação e desenvolvimento urbano, serviços estatísticos e de informação, inovação legislativa, estabilidade do gabinete, clínicas familiares, sensibilidade da burocracia, instrumentos de política industrial, gastos com unidade sanitária local, capacidade de efetuar gastos na agricultura.
} 
satisfação popular com os governos do Norte levou Putnam a fazer a seguinte indagação: "O que diferencia as regiões do Norte com bom desempenho das regiões do Sul com mau desempenho e, em cada uma dessas partes, as mais prósperas das menos prósperas?" (PUTNAM, 2006).

O pesquisador descartou a hipótese que associava a democratização à modernização econômica, uma vez que as regiões que tiveram melhor desempenho institucional não coincidem com as que receberam mais recursos ou investimentos. Embora Putnam admitisse a existência de conexão entre modernidade econômica e democratização, ele percebeu que essa relação não era direta e que, portanto, deveria existir um elemento catalisador e que tal elemento catalisador é a existência de uma comunidade cívica.

Para Baiardi (1997), no entendimento de Putnam, retomar a vertente do pensamento político é de fundamental importância, diante da diminuição da capacidade de funcionamento dos Estados liberais. A redução progressiva do senso cívico entre os cidadãos é algo negativo para as democracias. O significado de comunidade cívica estaria na aquisição do direito de cidadania pela via da vida comunal e pelo crescente interesse por questões referentes à vida pública, sem renunciar, obviamente, aos direitos e às razões individuais.

A intensidade de participação na vida civil, na vida pública, faria com que na comunidade cívica os cidadãos avaliassem e valorizassem seus interesses pessoais em um contexto mais global, de interesse público (BAIARDI, 1997). Por comunidade cívica, entende-se a disposição dos cidadãos para a busca do bem comum, algo mais que um campo de batalha, no qual se luta somente visando a obtenção de vantagens pessoais.

O debate filosófico em torno da categoria comunidade cívica tem destacado os seguintes elementos constitutivos: a) empenho cívico, que significaria participação ativa na vida comum; b) senso de igualdade política, medido pela propensão a estabelecer relações horizontais de reciprocidade e cooperação; c) solidariedade, confiança e tolerância, estabelecidos através do respeito e da estima pelos concidadãos, mesmo quando na presença de acentuada diferença ideológica, o que tem levado ao rompimento do isolamento e à derrota do sentimento de desconfiança e d) impulso associativista, entendido como compromisso em construir estruturas cujo escopo seja a cooperação. (BAIARDI, 1997, p. 385-6).

Walter, Ranincheski, Marinho e Castro (2003, p. 3) indagam acerca da principal pergunta de Putnam em sua pesquisa de 20 anos em que comparou o norte da Itália e toda a sua pujança em termos de desenvolvimento econômico, e o Sul, conhecido pelo atraso econômico. Afirmam os autores: "talvez sua intenção primeira tenha sido facilitar a resposta a outra pergunta: o que é preciso e quais as condições necessárias para que dada região se torne desenvolvida". Para os autores é preciso considerar "que Putnam esclarece em seu livro mais conhecido, Comunidade e Democracia: a experiência da Itália moderna, que o principal objetivo é examinar as origens do governo eficaz" (PUTNAM, 2006).

Para Putnam, as regiões com maior índice de capital social, as "regiões cívicas", eram as que apresentavam maior crescimento econômico, ao contrário das regiões com menos associações e mais hierarquia política. Uma das explicações do autor está "na confiança: nas regiões cívicas as instituições públicas são eficazes, pois a comunicação entre os cidadãos aumenta, o consenso sobre decisões comunitárias se fortalece e as organizações sociais e a economia local se consolidam, o que gera cooperação voluntária" (WALTER; RANINCHESKI; MARINHO; CASTRO, 2003, p. 4).

Com mais facilidade se encontra em sociedades desenvolvidas um conjunto de características da organização social, como confiança, reciprocidade, normas e sistemas, que contribuem para aumentar a eficiência da sociedade e facilitam a coordenação de ações. Trata-se de estoques 
de capital social, elementos que definem uma comunidade ou sociedade cívica que tendem a ser cumulativos e a se reforçarem de forma mútua por meio de diferentes instituições e relações interpessoais. Neste contexto, o capital social é uma resposta de inteligência social que promove processos de cooperação, de ação coletiva, que se opõe ao individualismo social. É também um círculo virtuoso que redunda em estabilizadores sociais, por causa dos elevados níveis de cooperação, confiança, reciprocidade, civismo e bem-estar coletivo. "Numa sociedade caracterizada por amplos sistemas de participação cívica, na qual a maioria das pessoas acata as normas cívicas, é mais fácil identificar e punir a eventual transgressão, que se torna mais arriscada e menos tentadora" (PUTNAM, 2006; PIATA; PREIS, 2019, p. 135).

\section{O CORREDOR BIOCEÂNICO E A ORIENTAÇÃO DA AGENDA 2030, DA ONU}

O desenvolvimento sustentável é uma orientação fundamental da Agenda 2030 da ONU, sendo o Objetivo no 8 de tal Agenda basilar para pensar esse tipo de desenvolvimento que, não depende só da vontade política dos governantes, mas da vontade cívica da sociedade, que além de participar das decisões, precisa estar atenta em relação às políticas públicas de inclusão social e ainda vigilante em relação ao meio ambiente.

De acordo com vários autores, entre eles Sachs (2004) o desenvolvimento sustentável é um processo contínuo em que as preocupações humanas, sociais e ambientais visam à melhoria das condições de vida, e que para tanto é necessário capital social, que é desdobrado em cooperação, confiança, corresponsabilidade etc.

Neste sentido, são as populações locais reais, concretas, que precisam movimentar o seu próprio capital social, já que o desenvolvimento sustentável de uma região nasce à escala local, porque depende da das dinâmicas dos indivíduos que, desenvolvendo capacidades cooperativas e participativas, se associam em objetivos comuns.

O fato do Governo de Mato Grosso do Sul convidar setores importantes da sociedade para debater o empreendimento do Corredor Bioceânico é muito significativo. A perspectiva de inserir as universidades nas discussões, por meio de grupos de trabalho, é também fundamental, uma vez que estas poderão contribuir, por meio de estudos, para a solução de problemas pontuais, relacionados ao desenvolvimento sustentável, além de fomentar espaços de discussão e de cooperação e, assim, colaborar para a consolidação de capital social. Conforme demonstrado nas pesquisas de Putnam (2006), o acúmulo desse tipo de capital está intrinsecamente ligado ao de desenvolvimento econômico e social.

Pode-se afirmar para além de Putnam, que o desenvolvimento sustentável necessita sobremaneira de capital social acumulado, porque se apenas os empresários de transporte e os empresários do agronegócio lucrarem com o Corredor Bioceânico, ela não será sustentável. É necessário que o dinheiro arrecadado com os impostos e com a exportações sejam investidos em políticas públicas de melhoria da cidade, no que tange principalmente ao saneamento básico, à geração de renda e à educação.

O capital social, como elemento nuclear para o desenvolvimento sustentável das localidades, alicerça-se no princípio de que este desenvolvimento deriva do contexto endógeno que lhe é inerente, daí que, qualquer transformação económica, social ou política seja fruto de relações de reciprocidade, cooperação, confiança e entendimento entre os diferentes atores locais (DUQUE, 2014). 
Na página oficial da Prefeitura de Porto Murtinho, no link História, narra-se que a cidade tem como cenário principal, a exuberância do Rio Paraguai e que o município possui mais de 100 anos e se destaca por ter sido "palco de uma série de acontecimentos marcantes na história do no País, como a Guerra da Tríplice Aliança e a Revolução de Getúlio Vargas de 1932". E ainda que tal localidade se destaca "por ser considerado um dos municípios mais importantes para o desenvolvimento de Mato Grosso do Sul, pois, devido ao Porto de exportações, passou por ciclos econômicos importantes que à época impulsionaram a economia do Estado". Também no mesmo site, encontram-se informações sobre solo, hidrografia, extensão territorial e demografia.

\section{População residente e densidade demográfica}

\begin{tabular}{|c|c|c|c|c|}
\hline Total & Urbana & Percentual & $\begin{array}{c}\text { Área total } \\
\mathrm{Km}^{2}\end{array}$ & $\begin{array}{c}\text { Densidade demográfica } \\
\text { Hab./Km² }\end{array}$ \\
\hline 15.372 & 10.059 & $65,00 \%$ & 17744,5 & 0,87 \\
\hline
\end{tabular}

Fonte: Dados da Prefeitura de Porto Murtinho, 2019, com base no senso IBGE de 2010.

\section{População residente, por situação do domicílio e sexo}

\begin{tabular}{|c|c|c|c|c|c|c|}
\hline Total & $\begin{array}{c}\text { Total } \\
\text { Urbana }\end{array}$ & $\begin{array}{c}\text { Total } \\
\text { Rural }\end{array}$ & $\begin{array}{c}\text { Homens } \\
\text { Urbana }\end{array}$ & $\begin{array}{c}\text { Homens } \\
\text { Rural }\end{array}$ & $\begin{array}{c}\text { Mulheres } \\
\text { Urbana }\end{array}$ & $\begin{array}{c}\text { Mulheres } \\
\text { Rural }\end{array}$ \\
\hline 15.372 & 10.059 & 5.313 & 5.073 & 3.161 & 4.986 & 2.152 \\
\hline
\end{tabular}

Fonte: Dados da Prefeitura de Porto Murtinho, 2019, com base no senso IBGE de 2010.

Ora, o Jornal Correio Brasiliense, em 24 de janeiro de 2019, publicou matéria, que informa que Porto Murtinho foi um dos últimos municípios do Estado a ter o acesso pavimentado, pela BR-267, de $213 \mathrm{~km}$. O que mostra que mesmo tendo uma história de prosperidade, somente em 2013, teve seu acesso pela rodovia pavimentado. O Prefeito de Porto Murtinho, ainda segundo o jornal, acredita em uma transformação sem precedentes em sua região, em médio prazo, que beneficiará a população com a geração de empregos.

Porto Murtinho tem uma população hoje de menos de 16 mil habitantes, mas certamente irá aumentar quando o Corredor estiver funcionando, o que vai implicar infraestrutura urbana e efetivação de políticas de geração de renda, sob pena de ser um espaço em que será destaque pela prostituição infantil e por problemas ambientais. Pelo que se lê no site oficial da prefeitura, o município tem uma hidrografia privilegiada ${ }^{11}$ (o que é uma característica da região do Pantanal), cujos principais cursos de água são os rios "Perdido, Apa, Paraguai, Nabileque, Naitaca, Aquidabã, Tereré e Amonguijá. Os rios nascentes no município são o Aquidabã, Tereré, Branco e Amonguijá"

\footnotetext{
${ }^{11}$ Os rios córregos nascentes no município são o Tarumã, Jatobá, Limoeiro, Serrinha, Jibóia, Agua Fria, Ciena, Tomásia, Congonhas, Capivara, Getúlio, Laú-de-já, São Claro, Papagaio, Santa Teresa, Baguassú, Chatelodo, Rapadura, Triunfo, Lageado, Taquarussu, Formiga, São Paulo, Miguel, Santa Rosa, Figueira, Progresso e Sanga Funda. Vazantes: Bacaína, Apertado, Panela e Jacaré. A precipitação varia entre 1.100 a 1.800 mm anuais. Período da cheia. De novembro a março o nível das águas sobem, alagando grandes áreas. Nessa época os rebanhos são retirados para áreas mais altas. Período de seca: de abril a outubro o nível das águas voltam ao normal e os rebanhos voltam para o seu lugar de origem. Prefeitura de Porto Murtinho. Disponível em: http://www.portomurtinho.ms.gov.br/ indicadores/4/hidrografia. Acesso em: abr. 2019.
} 
(PREFEITURA DE PORTO MURTINHO, 2019).

O Corredor Rodoviário Bioceânico, ao mesmo tempo em que poderá vir a ser elemento catalisador de desenvolvimento local, para a região de Mato Grosso do Sul, incluído o município de porto Murtinho, ela também transcende as fronteiras do regional, uma vez que cortará mais três países, isto é, Paraguai, Argentina e Chile. Trata-se de um Corredor Rodoviário internacional ou transnacional.

A expedição organizada pelo governo estadual de Mato Grosso do Sul, entre os meses de agosto e setembro de 2018, e também noticiada pelo $\mathrm{G} 1^{12}$ percorreu os lugares por onde o Corredor será efetivado. O grupo saiu de Porto Murtinho e passou por Carmelo Peralta e Loma Plata, no Paraguai, seguiu para Pozo Hondo, Jujuy e Salta, na Argentina, e depois para são Pedro do Atacama, Iquique, Antofogasta, Mejillones e Calama no Chile.

Não resta dúvida de que se trata também de um Corredor muito importante para o turismo que também precisa ser sustentável, sobretudo porque passará por áreas de geleiras, com biomas e ecossistemas diferenciados, mas é necessário que o cuidado com os espaços destinados a essa atividade econômica, sejam monitorados e cuidados, pois não isso não ocorra será contraproducente para os próprios empreendimentos nessas áreas. Claro está que juntamente com o turismo haverá um grande intercâmbio cultural de trocas, a partir das quais também será necessário desenvolver a comunidade cívica de que fala Putnam, além do regional.

Na VII Reunião sobre Corredores Bioceánicos, realizada em Asunção, Paraguai, entre os días 03 e 04 de abril de 2019, por meio de painéis e mesas-redondas, professores e pesquisadores discutiram temas como infraestrutura, transporte, logística, produção e comércio. O último painel, o 4, formado pela Rede Universitária contou com a presença de instituições dos quatro países. Também os temas propostos para debates na Mesa-redonda 4 demonstraram que há uma articulação profícua entre as instituições universitárias e as autoridades governamentais.

Na página oficial do Governo do Paraguai ${ }^{13}$ há informações, em matéria publicada no dia 27 de fevereiro de 2019, acerca dos preparativos da VII Reunião. "La Cancillería Nacional convocó en fecha 25 de febrero una reunión interinstitucional preparatoria de la "VII Reunión de Corredores Bioceánicos", que se llevará a cabo en el mes de abril próximo en nuestro país". E dando seguimento à matéria, como forma de justificar a importância da reunião, completa: "La construcción de esta ruta tiene un valor estratégico muy importante para el Paraguay, nuestro país deberá hacer las obras e inversiones más importantes para implementar este corredor tales como el puente internacional Carmelo Peralta-Porto Murtinho y una nueva carretera de 632 km".

Entende-se que para o alcance do Corredor Bioceânico ser pleno, para além do aspecto puramente econômico, os governos regionais precisam implementar políticas públicas de promoção social, para evitar a exploração sexual, gerar renda para as populações pobres, promover intercâmbios culturais, por meio da valorização de culturas autóctones, e, sobretudo, criar políticas ambientais compensatórias relativas aos problemas ambientais que poderão ser agravados em razão do aumento da emissão de gases na atmosfera.

\footnotetext{
12 Disponível em: https://g1.globo.com/mato-grosso-do-sul/rila/noticia/otimismo-marca-conclusao-do-percursoda-rota-de-integracao-latino-americana.ghtml. Acesso em: 26 abr. 2019.

${ }^{13}$ CANCILLERÍA PREPARA VII REUNIÓN DE CORREDORES BIOCEÁNICOS A REALIZARSE EN PARAGUAY. Disponível em: http://www2.mre.gov.py/index.php/noticias/cancilleria-prepara-vii-reunion-de-corredores-bioceanicos-realizarseen-paraguay. Acesso em: 26 abr. 2019.
} 
Sabe-se que os impactos provocados por $\mathrm{CO}^{14}$ são nocivos ao meio ambiente e que numa rodovia de tal importância como a bioceânica, o número de carros trafegando será muito grande. $E$, que, portanto, para cuidar de todas estas questões é fundamental a criação e manutenção de espaços democráticos de discussão e de promoção de programas e projetos, visando ao desenvolvimento sustentável.

Barquero (2003) argumenta que, embora as eleições ofereçam aos cidadãos um mecanismo institucional para expressar seu ponto de vista pró ou contra o governo, "a história recente do Brasil, entretanto, tem mostrado que esse procedimento poliárquico, sem negar sua importância, não se tem constituído no fator de poder do cidadão". Barquero (2003, p. 89) afirma que chegamos a um momento histórico paradoxal, em que quase todos parecem ser favoráveis à democracia, mas poucos acreditam que um governo democrático possa fazer alguma coisa.

As palavras de Barquero são válidas para se pensar seriamente sobre a democracia. Claro está que a complexidade das sociedades modernas exige uma participação mais ativa do cidadão, bem como a formação de rede de confiança e cooperação. O voto por si só não garante a eficiência da representação do governante em relação à sociedade, de modo que é necessário fomentar o capital social.

O Corredor Bioceânico, por certo, oportunizará muitos avanços aos países que o integram. No entanto, os seus impactos negativos, que vão desde a grande emissão de CO2 na atmosfera, até os impactos sociais de exploração sexual infantil, passando por problemas de saneamento básico em Porto Murtinho precisam ser dimensionados, para que estes problemas não fiquem invisibilizados, em face aos dividendos econômicos.

\section{CONSIDERAÇÕES FINAIS}

No preâmbulo da Agenda 2030 da ONU (2015) está escrito que os 17 Objetivos de Desenvolvimento Sustentável e as 169 metas de tal documento estimularão a ação para os próximos 15 anos em áreas de importância crucial para a humanidade e para o Planeta, como assegurar que todos os seres humanos possam desfrutar de uma vida próspera e de plena realização pessoal, e que o progresso econômico, social e tecnológico ocorra em harmonia com a natureza.

As orientações e balizas da Agenda 2030 deixam clara a importância crucial do desenvolvimento sustentável em suas dimensões econômica, social e ambiental. O aspecto econômico, por si só, não necessariamente significa desenvolvimento humano e social, na medida em que dividir apenas os problemas com a sociedade e não as benesses econômicas geradas. $\mathrm{O}$ desenvolvimento econômico precisa estar associado a políticas públicas inclusivas de geração de emprego e renda e, ainda, com a educação e a saúde das pessoas.

Não resta dúvida de que Porto Murtinho e todos os territórios por onde passará o Corredor serão bastante impactados, positiva ou negativamente. Porto Murtinho, que nos interessa mais diretamente, será passagem obrigatória de todos que saem do país

\footnotetext{
${ }^{14}$ A concentração de $\mathrm{CO} 2$ na atmosfera deveria diminuir para atender as metas do acordo de Paris, mas ao contrário do que foi planejado e acordado, continua aumentando em ritmo perigoso. A NOAA (National Oceanic \& Atmospheric Administration), por meio da Global Monitoring Division, divulgou os dados do crescimento médio da concentração global de CO2 na atmosfera. Em 2018, o aumento foi de 2,39 partes por milhão (ppm). É um número menor do que os 3 ppm de 2015 e 2016, mas é maior do que o 1,89 ppm de 2017. Isto fez com que a média de 2010 a 2018 esteja em 2,4 ppm, número acima da média da década passada (2000-09) que foi de 2,0 ppm e muito acima da média da última década do século XX (1991-00) que foi de 1,5 ppm, Portanto, a despeito das variações sazonais, o efeito estufa continua aumentando em ritmo mais acelerado do que nas décadas anteriores (ALVES, 2019)
} 
pelo Corredor e também por todos que entram. Conforme dados do IBGE, divulgados na página oficial da Prefeitura, trata-se de um município bem pequeno, com menos de 16 mil habitantes, que certamente passará a ter sérios problemas de saneamento básico e infraestrutura urbana. De modo que estas questões também precisam estar na agenda da Prefeitura e do Governo do Estado de Mato Grosso do Sul.

Os Grupos de Trabalho e os Seminários sobre o Corredor Bioceânico, realizados com a participação de governos, empresas e universidades, a partir de 2016, são fatores positivos e via de formação de capital social em torno de tal corredor.

Os impactos sociais e ambientais decorrentes do Corredor, que aparecem muito pouco nos discursos oficiais, precisam ser debatidos pelos grupos de trabalho e pela sociedade, para que tal empreendimento possa, de fato, trazer desenvolvimento para todos e não somente para os grupos exportadores, de logística, ou de transporte.

\section{REFERÊNCIAS}

ALVES, José Eustáquio Diniz. Aumenta a concentração de CO² na atmosfera em 2018. Ecodebate, 2019. Disponível em: https://www.ecodebate.com.br/2019/02/11/aumenta-a-concentracao-de-co2-naatmosfera-em-2018-artigo-de-jose-eustaquio-diniz-alves/. Acesso em: 20 abr. 2019.

ANDRADE, Silvio. Porto Murtinho sai do isolamento e vira polo de exportação. Correio do Estado, 25 mar. 2019. Disponível em:

https://www.correiodoestado.com.br/economia/porto-murtinho-sai-do-isolamento-e-vira-polo-deexportacao/349721/. Acesso em: 26 abr. 2019.

BAIARDI, Amílcar. Fazendo a democracia funcionar ou a tradição cívica nas regiões italianas - comentários sobre a obra de Robert Putnam. Caderno CRH, Salvador, n. 26/27, p. 375-404, jan./dez. 1997. Disponível em: https://repositorio.ufba.br/ri/bitstream/ri/2215/1/RCRH-2006-206\%20ADM.pdf. Acesso em: 23 abr. 2019

BAQUERO, Marcello. Construindo uma outra sociedade: o capital social na estruturação de uma cultura política participativa no Brasil. Revista de Sociologia e Política, n. 21, p. 83-108, nov. 2003. Disponível em: file:///C:/Users/MARIA/Documents/000.1\%202019/POL\%C3\%8DTICAS\%20P\%C3\%9ABLICAS/ CONSTRUINDO\%20UMA\%20OUTRA\%20SOCIEDADE.pdf. Acesso em: 23 abr. 2019.

CASTRO, José. O Plano Belgrano, chave para o agronegócio no Norte da Argentina. Clarin, Buenos Aires, 6 mar. 2016. Disponível em: https://www.clarin.com/clarin-em-portugues/plano-belgrano-agronegociosnorte-argentina_0_HkeceaOwXx.html. Acesso em: 24 abr. 2019.

COLEMAN, J. S. Foundations of Social Theory. Cambridge: Belknap Press of Harvard University Press, 1990.

CRUZ, J. Bioceânica injetará R\$2 200 milhões na economia de MS no primeiro ano. Campo Grande News, 27 dez. 2018. Disponível em: https://www.campograndenews.com.br/cidades/interior/bioceanica-injetarars-200-milhoes-na-economia-de-ms-no-primeiro-ano. Acesso em: 24 abr. 2019.

DAWALIBI, N. W.; GOULART, R. M. M.; AQUINO, R. C.; WITTER, C.; BURITI, M. A.; PREARO, L. C. Índice de desenvolvimento humano e qualidade de vida de idosos frequentadores de universidades abertas para a terceira idade. Psicologia \& Sociedade, v. 26, n. 2, 496-505.Disponível em: http://www.scielo.br/pdf/ psoc/v26n2/a25v26n2.pdf. Acesso em: 23 abr. 2019.

DUQUE, Eduardo. Capital social como instrumento de desenvolvimento sustentável. Revista de Sociologia Configurações, 22 set. 2014, p. 189-201. Disponível em: http://configuracoes.revues.org/1862. Acesso em: 24 abr. 2019. 
MATO GROSSO DO SUL (Estado). Corredor Bioceânico. Portal transparência, (s.d.). Disponível em: http:// www.corredorbioceanico.ms.gov.br/foco-em-cada-regiao/. Acesso em: 24 abr. 2019.

MIRANDA, E. Rota Bioceâncica será nova fronteira do turismo em quatro países, diz Fernando Schmidt, embaixador do Chile no Brasil. Correio do Estado, 13 dez. 2018. Disponível em: https://www. correiodoestado.com.br/cidades/rota-bioceanica-sera-uma-fronteira-do-turismo-em-quatro-paisesdiz/343038/. Acesso em: 24 abr. 2019.

ORGANIZAÇÃO DAS NAÇÕES UNIDAS (ONU). Agenda 2030, 2015. Disponível em: https://nacoesunidas. org/pos2015/agenda2030/. Acesso em: 24 abr. 2019.

PIAIA, T. C.; PREIS, M. A. Deveres fundamentais: contribuições ao desenvolvimento das "virtudes cívicas", do "capital social" e da "confiança". Revista Direitos Fundamentais \& Democracia, v. 24, n. 1, p. 126-142, jan./abr. 2019. Disponível em: http://revistaeletronicardfd.unibrasil.com.br/index.php/rdfd/article/ view/1419. Acesso 24 abr. 2019.

PUTNAN, R. D. Comunidade e democracia: a experiência da Itália moderna. 5. ed Tradução de Luiz Alberto Monjardim. Rio de Janeiro: Editora FGV, 2006.

REPÚBLICA DEL PARAGUAY. Cancillería prepara VII Reunión de Corredores Bioceánicos a realizarse en Paraguay. 27 fev. 2019. Disponível em: http://www2.mre.gov.py/index.php/noticias/cancilleria-preparavii-reunion-de-corredores-bioceanicos-realizarse-en-paraguay. Acesso em: 26 abr. 2019.

ROTA BIOCANICA injetará 200 milhoes na economia de MS. Top Midia News, 2 jan. 2019. Disponível em: https://www.topmidianews.com.br/economia/rota-bioceanica-injetara-r-200-milhoes-na-economia-dems/103315/. Acesso em: 26 abr. 2019.

SACHS, I. Desenvolvimento: includente, sustentável, sustentado. Rio de Janeiro: Garamond, 2004.

TAVIEIRA, M. S. Capital turístico e as teorias sociais de Marx, Bourdieu e Putnam. Revista Turismo em Análise, São Paulo, v. 27, n. 1, jan./abr. 2016. Disponível em: https://www.revtur.org/scielo.php?script=sci_ arttext\&pid=S1984-48672016000100004. Acesso em: 23 abr. 2019.

VIEGAS, A. Viabilização da Rota Bioceânica deve transformar MS em 'hub' de exportação e importação, prevê secretário. G1 MS, 24 dez. 2018. Disponível em: https://g1.globo.com/ms/mato-grosso-do-sul/ noticia/2018/12/24/viabilizacao-da-rota-bioceanica-deve-transformar-ms-em-hub-de-exportacao-eimportacao-preve-secretario.ghtml. Acesso: 24 abr. 2019.

WALTER, M. I. M. T.; RANINCHESKI, S.; CASTRO, H. C. O. Capital Social e políticas sociais no Brasil: diferenças regionais em população beneficiária de programas sociais. In: CONGRESSO BRASILEIRO DE SOCIOLOGIA, 11., 1-5 set. 2003, Campinas. Anais [...]. São Paulo: UNICAMP, 2003: Desigualdades Sociais. Disponível em: file:///C:/Users/MARIA/Downloads/sbs2003_gt04_maria_walter.pdf. Acesso em: 24 abr. 2019.

\section{Sobre os autores:}

Maria Geralda Miranda - Pós-doutoranda em Políticas Públicas e Formação Humana na Universidade do Estado do Rio de Janeiro (UERJ). Pós-doutora em Estudos de Literaturas Africanas de Língua Portuguesa pela UFRJ. Doutora em Letras com ênfase em estudos pós-coloniais, e mestre em Literatura Comparada com ênfase nos estudos culturais pela Universidade Federal Fluminense (UFF). Especialista em Literaturas Vernáculas pela UERJ. Graduada em Comunicação Social (Jornalismo) e em Letras Clássicas e Vernáculas pela UERJ. Professora do Programa de Pós-Graduação em Desenvolvimento Local, do Centro Universitário Augusto Motta, UNISUAM. Coordenadora do Projeto "Implicações do Ambiente no processo 
de Ensino-Aprendizagem: Estudos sobre escolas Públicas do Complexo do Alemão, na Cidade do Rio de Janeiro". E-mail: mariamiranda@globo.com, Orcid: http://orcid.org/0000-0002-2461-7414

Reis Friede - Doutor e mestre em Direito Público pela Universidade Federal do Rio de Janeiro (UFRJ), e mestre em Direito do Estado pela Universidade Gama Filho (UGF). Desembargador Federal. Membro Titular do Órgão Especial e Diretor do Centro Cultural Justiça Federal (CCJF). Professor Emérito da Escola de Comando e Estado-Maior do Exército (ECEME). Professor Honoris Causa da Universidade da Força Aérea (UNIFA). Conferencista Emérito da Universidade Castelo Branco (UCB). Professor de Direito Constitucional da Escola da Magistratura do Estado do Rio de Janeiro (EMERJ). E-mail: reisfriede@hotmail.com, Orcid: http://orcid.org/0000-0001-9316-3690

Katia Avelar - Doutora em Ciências e mestre em Ciências Biológicas pela Universidade Federal do Rio de Janeiro (UFRJ). Graduação em Farmácia e Bioquímica pela Universidade Federal de Juiz de Fora. Coordenadora do Laboratório de Referência Nacional para Leptospirose do Instituto Oswaldo Cruz (FIOCRUZ). Professora Titular e Pesquisadora do Programa de Pós-Graduação Profissional Interdisciplinar em Desenvolvimento Local do Centro Universitário Augusto Motta (UNISUAM). E-mail: katia.avelar@gmail.com, Orcid: http://orcid.org/0000-0002-7883-9442 